\title{
SOIL-INCORPORATION OF FUNGICIDES FOR CONTROL OF CLUBROOT OF VEGETABLE BRASSICAS
}

\author{
L-H. CHEAH, B.B.C. PAGE and J.P. KOOLAARD \\ New Zealand Institute for Crop \& Food Research Limited, \\ Private Bag 4005, Levin
}

\begin{abstract}
The efficacy of four fungicides (benomyl, mancozeb, fluazinam and flusulfamide in nine treatments) as soil-incorporations or soildrenches for control of clubroot was evaluated on Chinese cabbage 'Wong Bok' in clubroot-infested land. Each fungicide suspension was sprayed onto trial plots, rotary-hoed into the soil and plots were then planted with seedlings. The benomyl suspension was drenched about the root system after transplanting seedlings. Soil-incorporation of mancozeb $(3.0 \mathrm{~kg} / \mathrm{ha})$, flusulfamide $(1.2 \mathrm{~kg}$ and $2.4 \mathrm{~kg} / \mathrm{ha})$ and fluazinam $(2.0 \mathrm{~kg} / \mathrm{ha})$ reduced clubroot severity. All treatments (except fluazinam at $1.5 \mathrm{~kg} / \mathrm{ha}$ ) gave higher plant top weights than the untreated control. Soil-incorporation of fungicides was less labour-intensive and time consuming than soil drenching.
\end{abstract}

Keywords: Chinese cabbage, clubroot, disease control, fungicides, Plasmodiophora brassicae, soil-incorporation.

\section{INTRODUCTION}

Clubroot of brassicas, caused by the protozoanPlasmodiophora brassicae continues to be a serious problem throughout New Zealand vegetable brassica-growing areas. It has long been recognised as an economically important disease that is difficult to control. Many fungicides have been tested for efficacy against $P$. brassicae. Compounds that have given good control of clubroot include: benomyl, captafol (Tate 1977; Tate and Cheah 1983), chlorothalonil, fostyl-Al, thiabendazole and thiophanate-methyl (Humpherson-Jones 1993). More recently, new fungicides (e.g. fluazinam and flusulfamide) and mancozeb have also been found to be effective (Humpherson-Jones 1993; Dixon et al. 1994). Of these, only benomyl and a mixture product of chlorothalonil plus thiophanate-methyl are registered in New Zealand as transplant and soil-drench treatments for clubroot control (O'Connor 1994).

In the last three seasons (1995-97), good clubroot control has been achieved with soil-incorporated calcium cyanamide (Cheah 1995). We have also found that fluazinam, flusulfamide and mancozeb soil drench treatments gave effective control of the disease (Falloon et al. 1997). Through frequent contact with brassica growers regarding the practical use of these effective fungicides for clubroot control, we were advised that further research was required on more practical methods of fungicide application that were cost-effective and less labour intensive. The objective of this study was to evaluate promising fungicides as a soil-incorporated treatment for control of clubroot.

\section{Trial establishment}

\section{METHODS}

A trial was carried out in clubroot-infested Dannevirke silt loam (pH 6.2) on 10 September 1997 near Levin. The soil was thoroughly cultivated. Fungicide treatments were prepared as suspensions to give the desired concentrations (Table 1). These were band sprayed using knapsack sprayer (150-200 kpa) onto trial plots and then rotaryhoed into the soil to a depth of about $15 \mathrm{~cm}$. Chinese cabbage cv. Wong Bok seedlings (8 weeks old) were immediately transplanted into the plots. Control plots were sprayed 
with water and rotary-hoed. Benomyl (standard control) suspension was drenched by hand about the root systems of the transplants. Each treatment plot consisted of a single row of 20 plants, spaced at $0.3 \mathrm{~m}$ with $1.0 \mathrm{~m}$ spacing between rows. The experimental design was a randomised block with five replications. Crop management followed routine commercial practices.

\section{Disease assessment}

Plants were harvested at maturity (24 November 1997) and individual plant top weights were measured. All root systems were lifted and scored for club root on a 0 4 scale, where $0=$ healthy roots and $4=$ completely clubbed.

\section{Statistical analysis}

A non-parametric test (Kruskal and Wallis 1952) was used to compare disease scores among treatments because data were highly skewed. Analysis of variance was used for the top weight data. This method uses the ranking of the observations to compare treatments. Analyses were carried out using the Minitab statistical programme.

\section{RESULTS}

All the experimental plots were severely infested with clubroot as indicated by generally high scores (4) in all plots (Figure 1). The non-parametric test indicated that treatments 4 and 6 had reduced $(\mathrm{P}<0.1)$ clubroot severity compared to the control and treatments 5 and 9 also gave some reduction $(\mathrm{P} \approx 0.13$ and $\mathrm{P} \approx 0.3$ respectively). The benomyl soil-drench did not control the disease. When comparing individual chemical groups (mancozeb, flusulfamide and fluazinam), flusulfamide gave a lower severity score than mancozeb $(\mathrm{P} \approx 0.11)$ and fluazinam $(\mathrm{P}<0.05)$. All treatments (except treatment 8 ) gave greater top weights than the untreated control (Table 1). Treatments $6(\mathrm{P}<0.05), 2$ and $5(\mathrm{P}<0.10)$ gave significantly heavier top weights than the untreated control.

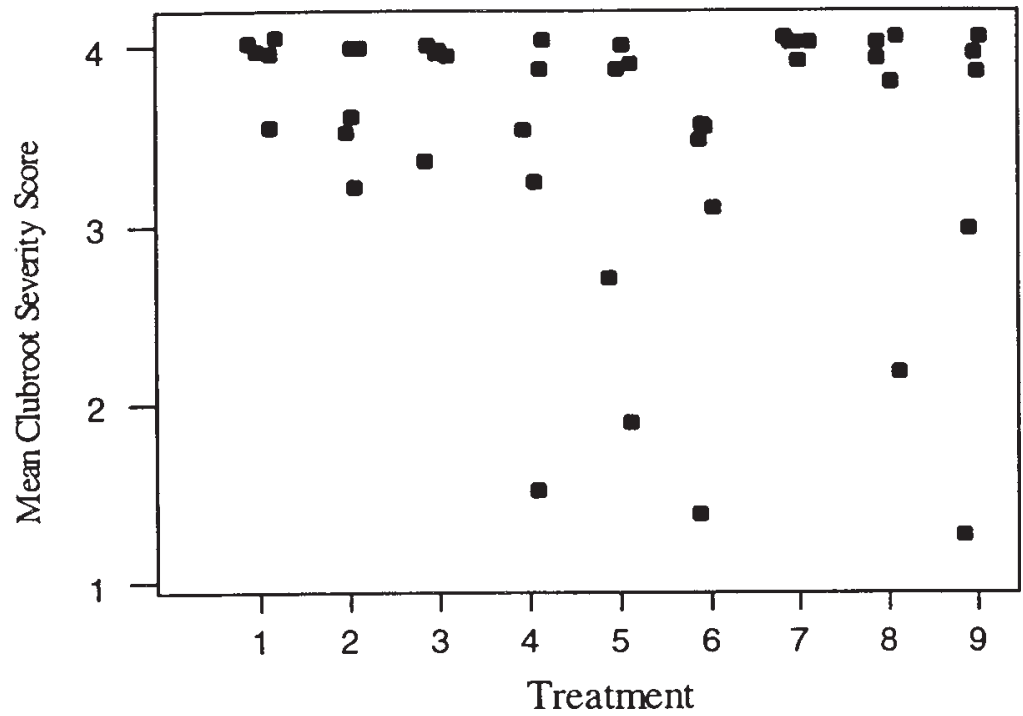

FIGURE 1: Distribution of mean clubroot severity scores on Chinese cabbage 'Wong Bok' roots for each fungicide treatment. (Fungicide treatments as in Table 1). 


\section{TABLE 1: Mean top weight of Chinese cabbage 'Wong Bok' plants harvested from field plots of clubroot-infested soil to which different fungicide treatments had been applied.}

\begin{tabular}{llc} 
No. & Treatment & $\begin{array}{c}\text { Mean top weight } \\
\text { (g/plant) }\end{array}$ \\
\hline 1 & Untreated control (water; soil-incorporated) & 245 \\
2 & Benomyl (soil drench; 0.1 g ai/200 ml/plant) & 383 \\
3 & Mancozeb (soil-inc.; $1.0 \mathrm{~kg} \mathrm{ai} / \mathrm{ha})$ & 293 \\
4 & Mancozeb (soil inc.; 3.0 kg ai/ha) & 283 \\
5 & Flusulfamide (soil-inc.; $1.2 \mathrm{~kg} \mathrm{ai} / \mathrm{ha})$ & 362 \\
6 & Flusulfamide (soil-inc.; $2.4 \mathrm{~kg} \mathrm{ai} / \mathrm{ha})$ & 402 \\
7 & Fluazinam (soil-inc.; $0.7 \mathrm{~kg} \mathrm{ai} / \mathrm{ha})$ & 319 \\
8 & Fluazinam (soil-inc.; $1.5 \mathrm{~kg} \mathrm{ai} / \mathrm{ha})$ & 232 \\
9 & Fluazinam (soil-inc.; $2.0 \mathrm{~kg} \mathrm{ai} / \mathrm{ha})$ & 313 \\
LSD (P =.05; df = 35) & 149
\end{tabular}

${ }^{1} 20$ plants per plot.

\section{DISCUSSION}

In this trial, the presence of high inoculum of $P$. brassicae in all plots provided a rigorous test of the treatments for their ability to control clubroot. The results showed that some treatments applied as soil-incorporations were effective for clubroot control, and also increased plant top weight. Although the benomyl soil-drench (a recommended control method) did not significantly reduce disease severity, it did increase the top weights. Similar results have been observed in a previous trial (Cheah and Page 1997), where benomyl drenches significantly increased yield while providing only marginal disease control. Benomyl has also been reported to stimulate yield in cauliflower crops (Cheah et al. 1981).

In two separate trials carried out at the same time (not reported here), we also found that soil-drenches of the same treatments were not effective. This is probably because a limited area around the root zone was treated when fungicides were applied using a soil-drench method compared with a soil-incorporated application method. In addition, plants treated using the soil-drench method showed infection, or clubbing, generally on the tips of root systems, but the main (tap) roots were disease-free. This indicates that soil-drenching of fungicides was sufficient to protect the main root system but does not protect roots growing out of the drenched area.

Generally, only high rates of the fungicides gave significant reduction of clubroot. Lower rates may provide sufficient control when infection was not severe. Dixon et al. (1994) showed that soil-incorporation of flusulfamide at low rates $(0.6 \mathrm{~kg}$ and 0.9 $\mathrm{kg} / \mathrm{ha}$ ) significantly reduced clubroot in soil where the disease was not severe.

Our results suggest that fungicide treatment alone will not provide full protection against clubroot infection. In the last three seasons (1995-97), good progress has also been made toward identifying clubroot-resistant cultivars. We have found that Chinese cabbage 'Taler', broccoli 'Hanamori' and Brussels sprout 'Dolmic' are tolerant of the disease (Falloon et al. 1997). This study suggests that fungicides and disease resistance have potential as components of an integrated clubroot management strategy.

Soil incorporation of chemicals is less labour intensive and is also time- and costsaving compared with soil drenching. Soil incorporation of chemicals is therefore more likely to be accepted by brassica growers for clubroot control.

\section{ACKNOWLEDGEMENTS}

This research we funded by the Fresh Vegetable Research and Development Grants Committee of the NZ Vegetable and Potato Growers' Federation Inc. Elliot Chemicals Limited and Crop Care Holdings Limited supplied fungicides and Dr R.E. Falloon gave helpful advice. 


\section{REFERENCES}

Cheah, L-H., 1995. Calcium cyanamide for clubroot control in cauliflower. Proc. 10th Aust. Plant Pathology Conf:: 99.

Cheah, L-H., Corbin, J.B. and Hartill, W.F.T., 1981. Control of light leaf spot of brassicas (Pyrenopeziza brassicae Sutton \& Rawlinson) with fungicides. N.Z. J. Agric. Res. 24: 391-395.

Cheah, L-H. and Page, B.B.C., 1997. Trichoderma spp. for potential biocontrol of clubroot of vegetable brassicas. Proc. 50th N.Z. Plant Prot. Conf.: 150-153.

Dixon, G.R., Craig, M.A., Burgess, P.J. and Thomas, J.I., 1994. MTF 651: A new soil applied fungicide for the control of Plasmodial fungi. Brighton Crop Protection Conference, Pests and Diseases V2: 541-548.

Falloon, R.E., Nott, H.M., Cheah, L-H., Wright, P. and Growers, S., 1997. Integrated control offers best prospects. N.Z. Commercial Grower 52(3): 20-22.

Humpherson-Jones, F.M., 1993. Effect of surfactants and fungicides on clubroot (Plasmodiophora brassicae) of brassicas. Annals Appl. Biol. 122: 457-465.

Kruskal, W.H. and Wallis, W.A., 1952. Use of ranks in one-criterion variance analysis. J. Am. Stat. Assoc. 47: 583-621.

O’Connor, B., 1994. Novachem Manual. Novachem Service Limited, Palmerston North, New Zealand. 360 p.

Tate, K.G., 1977. Evaluation of benzimidazoles for clubroot control in transplanted cabbages. Proc. 30th N.Z. Weed and Pest Control Conf:: 96-100.

Tate, K.G. and Cheah, L-H., 1983. Control of clubroot in cauliflower. N.Z. Commercial Grower 38(9): 36. 